\title{
PEMIKIRAN TEOLOGIS EDUKATIF YOHANES CALVIN SERTA RELEVANSINYA BAGI PENDIDIKAN BERGEREJA MASA KINI
}

\author{
Jeane Marie Tulung, Yornan Masinambow \\ Institut Agama Kristen Negeri Manado \\ jeane.tulung@iakn-manado.ac.id \\ Diterima 29 Agustus 2019 \\ Disetujui 29 September 2019
}

\begin{abstract}
The purpose of this paper is to describe and understand how the thought of John Calvin who was a famous reformer figure from time to time. Calvin paid great attention to Christian education especially in the church. He arranged systematically the way, the content of the teaching, as well as the qualifications, self-image of the teachers both pastors and religious teachers who were all based on the Bible and to glorify God. The method used in this paper is a qualitative research method with a literature study study in which the researcher reviews, compares, formulates and analyzes Calvin's thoughts both in his life context, his thoughts through books, documents, journals and other relevant literature studies. From the findings it can be said that Calvin's educative theological thought is purely based on the Bible. For Calvin, the teaching of the Christian faith is determined by the Bible and interpretations that are right and right and can have a good influence on the church and society. Calvin is always thinking of the right way so that the quality of the faith of the congregation continues to develop well and can be implemented in a variety of social life. In the midst of challenges today the church is required not to be carried away by various kinds of ideas that do not emphasize the Bible as the basis of human life. As it was done, Calvin the priests, teachers of religion today are required with full responsibility to think deeply about ways to continue to nourish the true Christian faith based on the Scriptures so that the quality of their faith is well preserved and lives glorifying God.
\end{abstract}

Keywords: Calvin, Christian Education, Church

\section{ABSTRAK}

Tujuan tulisan ini mendeskripsikan serta memahami bagaimana pemikiran Yohanes Calvin yang adalah seorang tokoh reformator yang termasyur dari zaman ke zaman. Calvin sangat menaruh perhatian yang begitu besar dan mendalam terhadap pendidikan Kristiani khususnya di gereja. Dia menyusun secara sistematis cara, isi pengajaran, serta kualitfikasi, citra diri para pengajar baik pendeta maupun guru agama yang semuanya berlandaskan Alkitab dan untuk memuliakan Allah. Metode yang digunakan dalam tulisan ini adalah metode penelitian kualitatif dengan kajian studi literatur di mana peneliti mengulas, membandingkan, merumuskan serta menganalisis pemikiran Calvin baik dalam konteks hidupnya, pemikirannya melalui buku-buku, dokumen, jurnal serta kajian literatur lainnya yang relevan. Dari hasil temuan dapat dikatakan bahwa pemikiran teologis edukatif Calvin murni berdasarkan Alkitab. Bagi Calvin, pengajaran iman Kristen ditentukan oleh Alkitab serta interpretasi yang benar dan tepat serta dapat memberikan pengaruh yang baik bagi gereja dan masyarakat. Calvin selalu memikirkan cara yang tepat agar kualitas iman jemaat terus berkembang dengan baik dan dapat dilaksanakan dalam berbagai macam kehidupan sosial masyarakat. Ditengah tantangan sekarang ini gereja dituntut untuk tidak terbawa arus dari berbagai macam paham-paham yang tidak menekankan Alkitab sebagai dasar kehidupan manusia. Seperti yang dilakukan, Calvin para pendeta, guru agama saat ini dituntut dengan penuh tanggung jawab untuk memikirkan secara mendalam cara untuk terus memberikan nutrisi iman Kristen yang sungguh-sungguh berdasarkan Kitab Suci agar kualitas iman mereka terjaga dengan baik dan hidup memuliakan Allah.

Kata Kunci: Calvin, Pendidikan Kristen, Gereja

\section{PENDAHULUAN}

Kehidupan kekristenan saat ini dipengaruhi oleh berbagai macam worldview yang ada, misalnya munculnya pandangan filosofis manusia misalnya; 
romantisisme, rasionalisme, empirisisme, pragmatisme juga eksistensialisme yang diperhadapkan kepada umat Kristen, dan ditantang untuk mempertanyakan inti iman mereka. Sepanjang sejarah pandanganpandangan tersebut menggoda dan juga menuntun orang Kristen untuk bertanggung jawab terhadap iman kepercayaan mereka dan dapat memberikan suatu kontribusi dalam kehidupan mereka baik dalam keluarga, masyarakat maupun dalam jemaat. Manusia dicipta dengan sifat agama, moral dan hukum yang dengan pengertian tersebut untuk menghadirkan suatu paradigma baru berdasarkan worldview yang ada agar hidup setiap manusia terus mengarah kepada hal yang lebih baik lagi.

Gereja sebagai suatu wadah untuk bersandar serta setia memberitakan Firman Tuhan kepada umat Tuhan sebagai hal yang utama dalam kehidupan kekristenan. Gereja mempunyai tugas yang menyatakan fungsinya di dunia ini. Ia mempunyai misi dan tugas yang diembannya untuk memproklamasikan Injil ke seluruh dunia dan mengajar umatnya serta dunia tentang ajaran-ajaran Tuhan Yesus. ${ }^{1}$ Tugas gereja yang harus terus dilakukan dalam merawat umatnya adalah Ibadah, Persekutuan, Pengajaran, Misi, Pelayanan Pastoral.

1 Eli Tanya, Gereja dan Pendidikan Kristen: Mencermati Peranan Pedagogis Gereja. (STT:Cipanas, 1999) p.2
Salah satu tugas gereja yang penting serta dapat menjadi suatu landasan pertumbuhan Iman umat Tuhan adalah pengajaran atau pendidikan dalam konteks di gereja. Pendidikan merupakan hal utama dalam kehidupan manusia, dikarenakan didalamnya meliputi proses interaksi, berpikir, bersikap, keterampilan melalui pembelajaran.

Secara umum pendidikan dimengerti sebagai semua perbuatan dan usaha dari generasi tua untuk mengalihkan pengetahuan, pengalaman, kecakapan, serta keterampilan kepada generasi muda; sebagai usaha menyiapkan mereka agar dapat memenuhi fungsi hidupnya baik seara jasmani maupun rohani. Pengertian di atas menyatakan bahwa pendidikan adalah merupakan usaha atau upaya sadar tujuan atau bersahaya dari generasi yang satu ke generasi yang lainnya.

Van Til dan Berkhof memiliki pemikiran yang begitu penting bahwa prinsip hidup orang percaya adalah mampu memahami dan menjelaskan secara mendalam dan berakar mengenai pendidikan di gereja, yakni sebagai suatu fondasi sistem pemikiran Kristen yang selalu mempresuposisikan Tuhan yang sejati sebagai dasar pengetahuan dalam proses pembelajaran. $^{2}$

${ }^{2}$ Louis Berkhof dan Cornelius Van Til, Dasar Pendidikan Kristen, (Surabaya: Momentum, 2004) p.13 
Pendidikan bergereja selalu melihat warga gereja sebagai ciptaan Tuhan yang harus terus diberi nutrisi Firman yang sejati. Melalui pendidikan bergereja, warga gereja akan dibawa ke dalam kehidupan gereja yang sesuai dengan pekerjaan yang telah Tuhan persiapkan bagi umat-Nya. Gereja merupakan pusat pengajaran Iman Kristen yang bertujuan untuk menumbuhkan iman jemaat melalui berbagai macam pengajaran baik sekolah minggu, katekisasi, khotbah, pembinaan warga gereja juga keterlibatan jemaat dalam pelayanan sosial serta kelompok persekutuan jemaat. Berbicara mengenai pendidikan di gereja tidak akan terlepas dari peran pendidik di gereja yakni pendeta. Charles A. Tidwell dalam bukunya "Educational Ministry of a Churh", mengatakan bahwa,

"Ministers who serve as pastors must not fall prey to the misconception that a pastor can fulfill the responsibilities of ministry without an emphasis on education teaching and learning. Even those who have other ministers or laymen responsible for giving specialized leadership to the educational ministry of a church must not relinguish their responsibilities of being pastor to the educational ministry." 3

\footnotetext{
${ }^{3}$ Charles A. Tidwell, Educational Ministry of a Church, (Nashville: Broadman Press,) p.16
}

Pendeta sebagai naradidik di gereja adalah juga manager dan supervisor dari seluruh kegiatan pendidikan Kristen yang ada dalam gerejanya. Ia harus tahu dan mengerti pendidikan dalam gerejanya. Pendeta juga sebagai nara didik bertugas untuk merancang suatu program pendidikan Kristen dalam jemaatnya dengan melibatkan para majelis dan orangorang berkompeten di bidang pendidikan. Selain itu, dalam mengembangkan suatu pendidikan atau pengajaran di gereja, pendeta bekerja sama dengan sinode gerejanya. Karena pendidikan Kristen di gereja bukanlah tanggung jawab gereja local saja, tetapi merupakan tanggung jawab dan kebutuhan gereja secara sinodal. ${ }^{4}$

Sejarah mencatat bahwa ada banyak tokoh-tokoh yang memberikan suatu kontribusi besar dalam kemajuan pendidikan bergereja. Salah satu tokoh yang sangat terkenal bahkan pemikiran dan pengajarannya begitu berpengaruh adalah Yohanes Calvin yang merupakan tokoh reformasi gereja. Calvin memiliki perhatian khusus terhadap aspek pendidikan gerejawi yakni proses pembelajaran Kitab Suci bagi pelayan-pelayan Tuhan dan jemaat pada akhirnya semangat tersebut melahirkan

4 Homrighausen, Pendidikan Agama Kristen, (Jakarta: BPK Gunung Mulia, 2003) pp.7071 
sistem pendidikan di semua level, di luar lingkup gereja.

Dalam artikel ini, akan dijelaskan bagaimana gereja perlu melihat dan menelusuri lebih dalam lagi pemikiran Calvin yang sistematis dalam ranah pendidikan bergereja agar jemaat memahami, memaknai serta berefleksi akar pendidikan Kristen di gereja yang terus memuliakan Tuhan dalam kehidupan bergereja dan bermasyarakat.

\section{METODE PENELITIAN}

Jenis penelitian yang digunakan dalam makalah ini adalah penelitian kualitatif. Sumber data penelitian yang digunakan untuk menganalisa dalam penelitian ini adalah metode studi literature atau buku-buku yang membahas secara teologis edukatif, pemikiran Kristiani dengan kerja penelitian ilmiah yang menelaah secara kritis dan mendalam bahan-bahan pustaka yang relevan. Telaah ini dilakukan dengan cara mengumpulkan data atau informasi dari berbagai sumber pustaka yang kemudian disajikan dengan cara baru dan atau untuk keperluan baru. ${ }^{5}$

Penelitian tipe ini adalah penelitian kepustakaan yang bersifat deskriptif. Objek material penelitian ini adalah kepustakaan

\footnotetext{
5 Proposal Penelitian Kajian Pustaka (http//www.google.com)

${ }^{6}$ Kaelan M.S, Metode Penelitian Kualitatif bidang Filsafat, (Paradigma: Yogyakarta, 2005) p. 253
}

dari pemikiran seorang tokoh. Oleh karena itu, sumber data pada penelitian ini adalah berupa buku-buku kepustakaan. Penggunaan pelaksanaan penelitian ini adalah menggunakan metode deskriptif. ${ }^{6}$ Objek material penelitian ini adalah karya atau pemikiran seorang tokoh baik teolog maupun filsuf pada masa silam, oleh karena itu metode deskriptif historis diterapkan dalam rangka untuk mendeskripsikan konsep-konsep teologis edukatif serta paham-paham lainnya yang memengaruhinya. $^{7}$

Mengingat objek penelitian dari karya ilmiah ini maka pendekatan studi literatur yang digunakan adalah model kualitatif historis faktual, yaitu "analisis tekstual buku-buku teologis historis yang diinterpretasikan untuk mendapatkan makna dari teks keagamaan atau teks sosial atau fenomena kultural. ${ }^{8}$

$$
\text { Dalam aplikasinya terhadap }
$$
pemikiran teologis edukatif Yohanes Calvin, studi pustaka dengan model pendekatan kualitatif historis faktual. Pendekatan ini sengaja dipilih karena peneliti mengkaji pemikiran tokoh sejarah yang kemudian konsep pemikirannya dapat di relevansikan terhadap kehidupan masa kini dalam hal ini pendidikan bergereja.

${ }^{7}$ Ibid, p. 254

8 Andras B. Subagyo., Pengantar Riset Kuantitatif dan Kualitatif Termasuk Riset Teologi dan Keagamaan, (Bandung: Kalam Hidup, 2004), p.118. 
Karena itu, untuk mendapatkan makna pemikiran teologis edukatif dari tokoh Yohanes Calvin, maka peneliti melakukan analisis yang mendalam terhadap latar belakang kehidupan, pendidikan, pemikiran, pengaruh dari Calvin. Hal ini dilaksanakan oleh karena model pendekatan kualitatif historis faktual beranggapan bahwa suatu kegiatan analisis tertentu hanya dapat dipahami bersama dengan konteks tempat kegiatan itu muncul. ${ }^{9}$

Studi kepustakaan dalam penelitian ini adalah peneliti mengikuti cara dan arah pikiran seorang tokoh, dalam hal ini Yohanes Calvin itu sendiri, yakni pemikirannya mengenai pendidikan gerejawi dengan segala unsur metodis yang berlaku. Dimulai dengan mengumpulkan berbagai macam buku-buku, karya dan topik tokoh pribadi tersebut dan keterangan khusus tentang tokoh dan pemikirannya. ${ }^{10}$

\section{HASIL PENELITIAN}

\section{Riwayat Hidup dan Pendidikan Calvin}

Yohanes Calvin lahir pada tanggal 10 Juli 1509 sebagai Jean Cauvin di kota Noyon, Prancis Utara. Kemudian hari nama Cauvin, sesuai dengan kalangan kaum

\footnotetext{
${ }^{9}$ Ibid, p.119

10 Anton Bakker, Metodologi Penelitian Filsafat (Yogyakarta: Kanisius, 1989) p.63

${ }^{11}$ Christiaan de Jonge, Apa itu Calvinisme? (Jakarta: BPK Gunung Mulia, 2012) p.6
}

berpendidikan waktu itu, dilantinisasikan menjadi Calvinus. ${ }^{11}$ Ibu Calvin bernama Jeanne Lefranc. Ibunya adalah seorang wanita saleh dan cantik. Ia meninggal dunia ketika Calvin masih muda. Gerard Cauvin bekerja sebagai pegawai uskup Noyon. Pada awal mulanya ayah Calvin menginginkan anaknya untuk menjadi Imam. Pada umur 12 tahun Calvin sudah menerima "tonsur" (Pencukuran rambut dalam upacara inisiasi biarawan) dan ia sudah menerima upah dari paroki St. Martin de Marteville. Dengan penghasilan tersebut Calvin dapat meneruskan pendidikannya pada jenjang yang tinggi. Pada tahun 1523 Calvin memasuki College de la Marche di Park. Di sini ia belajar retorika dan Bahasa Latin. Bahasa Latin dipelajarinya pada seorang ahli bahasa yang terkenal, yaitu Marthurin Cordier. Kemudian ia pindah ke College de Montague. Di sini Calvin belajar theologia dan filsafat. $^{12}$ Ia kemudian melanjutkan studi untuk gelar Master of Arts di Montaigu, sebuah sekolah yang didirikan oleh Gerard Groote untuk mempersiapkan pendidikan kebiaraan yang ketat agar dapat mempersiapkan muridmurid menjadi imam. ${ }^{13}$

${ }^{12}$ F.D. Wellem, Riwayat Hidup Singkat Tokoh-tokoh Dalam Sejarah Gereja, (Jakarta: BPK Gunung Mulia, 2009) p.64

${ }^{13}$ HWB. Sumakul, Panggilan Iman dalam Teologi Luther dan Calvin ; suatu kajian Etika Sosial Politik dalam Gereja Reformasi, p.66 
Ada beberapa orang yang berpengaruh dalam proses pendidikan Calvin ketika ia mengikuti program Master of Art di Montaigu seperti yang dijelaskan oleh Bernard Cortret, yakni Maturin Cordier, Jan Standonck, Noel Bedier, Pierre Tempet. Dari beberapa nama orang di atas, Calvin lebih banyak belajar kepada Marturin Cordier, seorang guru bahasa Latin, yang menghargai para mahasiswa dengan mengoreksi jika ada sedikit kekeliruan yang dibuat ketika mereka belajar bahasa Latin. Oleh karena itu, ketika Calvin membuat tafsiran Surat 1 Tesalonika, buku itu dipersembahkan untuk guru tersebut yang waktu tafsiran itu dituliskan sudah menjadi kepala sekolah tinggi di Lausanne. ${ }^{14}$ Rancangan kurikulum tempat Calvin dilatih terdiri dari membaca buku-buku seperti metodologi filsafati exposito atau quastio (metode mengungkapkan dan menjawab pertanyaan yang diusulkan oleh naskah). ${ }^{15}$ Pelatihan berpikir semacam ini memberi dampak bagi pembentukan mentalitas diri Calvin dan nantinya diterapkan ketika ia harus berjumpa dan melayani di Gereja baik ketika ia masih berada di Perancis dan Jerman, maupun terutama ketika ia

${ }^{14}$ Bernard Cortret, Calvin: a Biography, translated by: M. Wallace McDonald, (Michigan: Publishing Company, 2000) p.15 menggagas dan mengembangkan reformasi Gereja di kota Jenewa.

Setelah menerima gelar licencie en arts, sebagai anak yang patuh, Calvin mengikuti ambisi ayahnya untuk belajar ilmu hukum di Orleans dan Bourges pada 1528. Hampir pasti ia tidak pernah melanjutkan studi filsafat. Ayahnya menarik Calvin dari Paris (1527-1528) supaya melanjutkan studi ilmu hukum di Orleans. Dalam ilmu hukum, Calvin belajar dari Pierre de L'Estoile dan Andre Alciati. Ia mempelajari retorika Cicero, filsafat abad pertengahan, silogisme, dan tentu berminat dalam bidang studi filologi humanis yang diterapkan ke dalam bidang naskah yuridis. ${ }^{16}$ Yang jelas, dengan belajar filologi, Calvin akhirnya menguasai bahasa Yunani dan Ibrani. Ia belajar bahasa Ibrani dari Francois Vatable. Dengan belajar dari rancangan kurikulum humanisme. Calvin dilatih untuk menelusuri bahasa-bahasa asli : Ibrani dan Yunani. ${ }^{17}$

Calvin mengawali kariernya sebagai Reformator di Jenewa dengan status pengajar Kitab Suci bagi Gereja Jenewa. Sebelum menjadi seorang pengkhotbah, ia adalah seorang guru. Tetapi ia segera ditugasi untuk berkhotbah dan untuk mengambil bagian dalam

\footnotetext{
15 THL. Parker, John Calvin, (Illinois Lion, 1975) p.9

${ }^{16}$ HWB Sumakul, Ibid, p.71

${ }^{17}$ Ibid,.p.72
} 
organisasi gerejawi. Maka sejak semula, empat bidang di mana nantinya ia melakukan karya yang benar-benar orisinil, eksegesis dan dogmatika, berkhotbah dan membentuk kembali Gereja terbuka bagi inisiatifnya. ${ }^{18}$ Calvin dikenal sebagai seorang pemikir yang hebat, sistematis, mendalam dan juga displin.

Selama Calvin hidup, tidak sedikit yang menjadi musuhnya - baik secara golongan (Roma Katolik dan Anabaptis) maupun pribadi (Servetus, Pierre Caroli, Jerome, Castellio, dan lain-lain) oleh sebab ajarannya yang tidak berkompromi. Bahkan, ia pernah diusir keluar dari Jenewa (1538), kota di mana ia dengan sepenuh hati memberikan pelayanannya, sebelum akhirnya diundang kembali (1541) setelah orang-orang Jenewa menerima Reformasi. Ketika meninggal, tidak banyak uang yang ia tinggalkan. ${ }^{19}$

\section{Karya-karya Yohanes Calvin}

Pada bulan April 1532, Calvin menerbitkan bukunya yang pertama, yaitu Komentar Kitab De Clementia. Dalam buku ini dipersembahkan kepada Claude de Hangest, sahabat sekolahnya di keluarga

\footnotetext{
${ }^{18}$ Francois Wendel, Calvin: Asal usul dan Perkembangan Pemikiran Religiusnya (Surabaya: Momentum, 2010) p. 43

${ }^{19}$ Ian Kamajaya, Ibid

${ }^{20}$ F.D. Wellem, Riwayat Hidup Singkat Tokoh-tokoh Sejarah Gereja, p.67

${ }^{21}$ David W. Hall dan Peter A. Lillback (ed.) Penuntun ke dalam Theologi Institutes Calvin: Esai-
}

bangsawan Mommer, di Noyon dahulu. Buku itu memperlihatkan Calvin sebagai seorang humanis sejati. Karya Calvin yang selanjutnya adalah sebuah buku teologi yang berjudul Psychopanychia (Mengenai tidurnya jiwa-jiwa), suatu karangan yang ditulis untuk melawan ajaran Anabaptis yang mengajarkan bahwa manusia tidur hingga Kristus datang kembali setelah manusia meninggal. ${ }^{20}$

Yohanes Calvin berusia dua puluh enam tahun ketika ia membuat naskah edisi pertama dari bukunya Institutes of the Christian Religion, yang diterbitkan pada tahun 1536. Kata Latin institution, kadangkadang dalam bentuk jamak institutions, seringkali digunakan dalam judul-judul buku abad keenam belas, dengan arti “pengajaran” atau "pendidikan”. Jadi judul Calvin berarti pengajaran dalam agama Kristen. ${ }^{21}$ Buku ini dianggap sebagai salah satu buku yang memengaruhi jalannya sejarah teologi. Melalui karya tersebut, Calvin terlihat sebagai seseorang yang memiliki pikiran jernih, sistematis, dinamis, kreatif dan transformatif. ${ }^{22}$

B. B. Warfield mengatakan bahwa: "The Institutes lies at the foundation of the

esai dan Analisis, Terj. Lanna Wahyuni, (Surabaya: Momentum, 2009) p.1

${ }^{22}$ Daniel Lucas Lukito, 500 Tahun Yohanes Calvin: Pengetahuan tentang Allah adalah Testing Ground untuk mengenal Manusia. (SAAT: Malang, Jurnal Veritas Vol.10. No.1, 2009) p.4 
whole development of Protestant Theology."23 Akademi Calvin, yang berdekatan dengan Katedral St. Pierre, memiliki dua level kurikulum : satu pendidikan umum bagi para pemuda Jenewa (kolese atau schola privata), dan yang satu lagi sebuah seminari untuk mendidik para hamba Tuhan (schola publica). ${ }^{24}$ Siapapun hampir-hampir tidak dapat mengabaikan dampak dari pendidikan umum bagi anak-anak muda, khususnya dalam suatu zaman ketika pendidikan pada dasarnya disediakan hanya untuk keturunan-keturunan aristokratis atau anggota-anggota masyarakat Katolik.

\section{Latar Belakang Calvin dalam Dunia Pendidikan}

Calvin berlatar belakang pendidikan humanis adalah bahwa keduanya menetapkan suatu keharusan bahwa paling tidak seseorang harus mendapat latihan dalam suatu pendidikan yang menyeluruh dan seluas mungkin, khususnya pembelajaran para tokoh klasik masa lalu. ${ }^{25}$ Dalam pendidikan yang baik ini, khususnya dalam kalangan reformator protestan, mereka berharap agar para pendeta, dalam pengertian khusus, harus

\footnotetext{
23 B.B Warfield, Calvin and Calvinism (Oxford: Oxford University Press, 1931) p.8

${ }^{24}$ Ibid, p.5

${ }^{25}$ François Wendel, Calvin: Origins and Development of His Religious Thought, trans., by
}

diperlengkapi dengan suatu tingkatan yang tinggi mengenai budaya intelektual. Suasana pendidikan dan semangat protestantisme yang tinggi dalam konteks abad pertengahan memberikan kerinduan yang besar dalam diri Calvin untuk mewujudkan impiannya dalam dunia pendidikan yang unggul dan berkualitas. ${ }^{26}$ Dalam hal ini para pelayan firman tidak dapat menjadi pelayan yang baik, jikalau mereka tidak terlatih dengan baik dalam disiplin ilmu sosial dan ilmu alam.

Pada masa itu selama satu abad di Skotlandia, seorang pelayan firman paling tidak sudah memperoleh gelar Bachelor of Arts atau sejenis dalam ilmu humaniora sebelum dia mempelajari ilmu - ketuhanan (divinities). Dengan dasar ini maka Akademi Jenewa yang didasarkan pada ide humanisme mengharuskan para pelayan belajar terlebih dahulu ilmu humaniora. Calvin mengakui bahwa pembelajaran disiplin ilmu yang lain selain belajar ilmu ketuhanan merupakan anugerah Allah dalam dunia ilmu pengetahuan. Jadi mempelajari filsafat, fisika, dialektika, dan matematika merupakan suatu keharusan dalam persiapan untuk menjadi pelayan firman yang baik. $^{27}$ Disini, Calvin

Philip Viret, (Grand Rapids: Baker Book House, 2000), p. 105

${ }^{26}$ Ibid, p. 107

27 John Calvin, Commentary on I Corinthians 1:20 in Commentary on the Epistles of Paul to the Corinthians; Institutes I. Xv. 6. 
mengakui kedaulatan Allah yang tertinggi dalam semua bidang ilmu pengetahuan dan manusia harus mengupayakan pembelajaran ini untuk kemuliaan namaNya.

\section{Pendidikan Bergereja menurut Calvin}

Dalam pendidikan bergereja, terdapat empat golongan yang dianggap para pelajar dalam pendidikan gereja. Calvin menyebutnya anak didik, namun ia tidak menggolongkan orang-orang menurut umur. Namun, para pelajar dapat diklasifikasikan atas empat kelompok yaitu anak-anak (dari bayi sampai pemuda). Orang dewasa, yang mengikuti pendidikan formal dari Sekolah Dasar sampai Perguruan Tinggi dan kaum Pendeta dan Pengajar. Jadi para pelajar atau juga disebut nara didik mencakup semua golongan usia, laki-laki dan perempuan. Identitas nara didik adalah berdosa namun telah dipilih Allah di dalam Yesus Kristus untuk diselamatkan. ${ }^{28}$ Kebaktian sangatlah penting bagi pendidikan bergereja menurut Calvin, karena ia memandang khotbah sebagai wadah yang disediakan Tuhan untuk mendidik setiap orang Kristen. ${ }^{29}$

\footnotetext{
28 Johanna Setlight, Suatu Peran Gereja dalam memperlengkapi Guru-guru Sekolah Minggu untuk Pelayanan Pendidikan Agama Kristen GMIM, (Tesis; Jakarta: SEAGEST, 1994) p.66

${ }^{29}$ Robert Boehlke, Sejarah Perkembangan Pikiran dan Praktek PAK, p.415
}

Menurut Calvin, pengajar paling utama adalah Tuhan Allah. Dialah yang memprakarsai pengalaman dalam belajar dan mengajar. Tetapi, Tuhan Allah juga memakai orang-orang yang menaklukan diri kepada Firman-Nya. Dalam hal ini terdapat dua jenis jabatan gerejawi/pelayan Firman-Nya untuk mengajar Firman Tuhan dalam konteks pendidikan bergereja yakni Pendeta/Gembala atau guru (doctor, dalam arti aslinya seseorang yang mengajar). Disamping mengajar melalui khotbah, Calvin mendidik rakyat melalui kuliah umum yang diberikannya. Contoh itu mendorong para pengikutnya untuk melibatkan diri secara langsung dalam pelayanan pedagogis. $^{30} \quad$ Calvin menambahkan bahwa Pendeta atau para Pengajar harus pandai memusatkan pemikiran mereka pada ajaran gereja yang berdasarkan Kitab Suci, harus pandai menguasai dan mengajar Alkitab, pendeta adalah "teaching elder". Sebagai "teaching elder", Pendeta berfungsi mendidik seluruh warga jemaat. Tuhan menunjuk pengajarpengajar, pendeta-pendeta untuk menolong jemaat melalui usaha-usaha mereka dalam bidang pendidikan gereja. ${ }^{31}$ Calvin percaya teologi adalah bagian integral dari setiap

\footnotetext{
30 John Calvin, Commentary on Titus 1:1012; in Calvin's Commentaries vol. XXI, trans by. William Pringle. Institutes II.ii) pp.12-13

31 Richard Robert Osmer, A. Teachable Spirit: Recovering the Teaching Office in the Church (Westminster: John Knox Press, 1990) p.117
} 
aspek pendidikan. "Inti hikmat ilahi," ia berkata, "adalah sebagai berikut: dengan hati yang berpusat pada Tuhan melalui iman yang sejati, orang-orang berseru kepada-Nya, dan mereka melatih diri mereka melalui perenungan atas kebaikankebaikan-Nya dengan maksud untuk menopang iman mereka kepada-Nya." ${ }^{32}$

Dalam konteks di mana Calvin dan mengajar khususnya di Jenewa, ia sangat menekankan disiplin, kesalehan, kerajinan, kebersihan dan moralitas dalam pendidikan bergereja. Disiplin moral dilakukan dengan menasehati dan mengingatkan nara didik dengan lemah lembut. Para pendidik harus menjadi contoh yang baik bagi nara didik. Mereka diharapkan menjadi pendidik dengan roh yang lemah lembut dan sopan serta tidak kasar. ${ }^{33}$ Dengan kata lain, seorang pendidik Kristen adalah seorang yang telah mengalami anugerah dilahirkan kembali dalam Kristus dan hidup dalam Kristus. Calvin mengingatkan gereja dan sekolah agar meningkatkan pola pembelajaran yang baik dalam semua bidang ilmu. Calvin berargumentasi bahwa Tuhan menghendaki agar setiap manusia ditolong dalam disiplin berbagai ilmu. ${ }^{34}$

Dalam penjelasan lebih lanjut dapat dikatakan bahwa Calvin menegaskan bahwa tujuan pembelajaran yang baik bagi

\footnotetext{
${ }^{32}$ Kalvin Budiman, Calvin dan lima pilar institusi sosial., p.203

${ }^{33}$ Ibid, p. 119
}

gereja adalah agar pengajaran tentang kebenaran dapat dipertahankan dan gereja terhindar dari kesalahan yang dibuat oleh para pendeta atau pengajar. Calvin adalah salah seorang reformator yang mampu menafsirkan suatu gerakan sebagai momen yang mampu merevitalisasi kehidupan religius, teologia, sosial-politik, ekonomi, serta pendidikan pada zamannya dan berefek sampai hari ini. Baginya, kebenaran ajaran dan teologi gereja ditentukan dan didasarkan pada Alkitab dan interpretasinya yang benar. Prinsip Sola Scriptura adalah penentu keberhasilan Reformasi Gereja. Dari prinsip ini akan ditemui prinsip-prinsip yang menyertainya, seperti Sola Gratia dan Sola Fide, termasuk Soli Deo Gloria.

Tugas Calvin, secara realistis sanggup memadukan doktrin iman kristen dan mengajarkannya dari sudut pandang pembinaan untuk warga jemaat secara sistematis dan alkitabiah. Calvin mampu mengajarkan kemuliaan Allah berdasarkan kebutuhan rohani pada zamannya yang secara esensi tidak bisa dilepaskan dari prinsip Alkitab. Gerakan Reformasi itu sangat biblikal karena menekankan pentingnya penafsiran Alkitab secara literal dan historis. Calvin adalah seorang gembala atau pendeta yang melayani di

34 Martin Febriana Lere Dawa, Peran Pendidikan Kristen Protestan John Calvin, (Jurnal Theologia Aletheia, 2005), p.32 
gereja. Di dalam pelayanan tersebut, ia berpikir dan menulis karya-karya teologinya selalu dari sudut pandang untuk pendidikan gerejawi atau pembinaan untuk warga jemaat. Ia sendiri mengatakan hal ini dengan jelas di dalam edisi perdana dari "Institutio"-nya bahwa karya tersebut ditujukan "terutama untuk masyarakat awam Prancis, di mana banyak di antara mereka yang lapar dan haus akan (pengenalan pada) Kristus." ${ }^{35}$ Itu sebabnya, tidak mengherankan jika gereja yang dilayani oleh Calvin di Geneva menjadi gereja model bagi gerakan Reformasi.

Dalam pendidikan yang baik ini, khususnya dalam kalangan reformator protestan, mereka berharap agar para pendeta, dalam pengertian khusus, harus diperlengkapi dengan suatu tingkatan yang tinggi mengenai budaya intelektual. Suasana pendidikan dan semangat protestantisme yang tinggi dalam konteks abad pertengahan memberikan kerinduan yang besar dalam diri Calvin untuk mewujudkan impiannya dalam dunia pendidikan yang unggul dan berkualitas. Paling tidak ada dua hal yang sangat mempengaruhi Calvin dalam kecintaannya terhadap dunia pendidikan. Yang pertama adalah pengalaman pendidikan terbaik yang pernah dia terima melalui seorang

35 Riwon Alfrey. Esensi dan Relevansi Teologi Reformasi. (Jakarta: Buletin Pillar GRII, 2007) p.130 pendidik humanis yang terkenal di Perancis, Mathurin Cordier, yang menjadi penasehat Calvin dalam mendirikan Akademi Jenewa. Kedua, pendidikan yang baik yang diterima Calvin dan juga berkat kesan-kesan mendalam dalam pengelolaan pendidikan dari Bucer dan Sturm di Stassbourg membuat Calvin bermimpi ke depan akan pendidikan yang lebih baik bagi gereja dan masyarakat di mana dia berada. Dorongan eksternal lainnya yang mendorong Calvin sebagai seorang pemerhati pendidikan adalah Calvin melihat kurangnya ketrampilan dari para pelayan dalam ilmu-ilmu sosial dan ilmu alam. Dalam hal ini para pelayan firman tidak dapat menjadi pelayan yang baik, jikalau mereka tidak terlatih dengan baik dalam disiplin ilmu sosial dan ilmu alam..

Senada dengan hal diatas, maka tujuan pendidikan gereja adalah untuk membina orang-orang yang ada di dalam Kristus. Orang yang datang harus melalui proses pembinaan agar mengalami hidup baru untuk mempersiapkan diri dalam memasuki hidup kekal. Jadi, tujuan utama adalah membawa manusia kepada Kristus. Dasar itulah yang menjadi pengajaran Calvin. Ia berusaha mendirikan sekolah terutama Akademi Jenewa yang menjadi perguruan tinggi bagi bakal pemimpin 
Gereja Pro-Reformasi di seluruh Eropa.

Calvin sendiri juga gemar belajar, dan tidak heran dalam teologi Calvin penekanan pentingnya khotbah dan pengajaran dalam teologi Calvin merupakan cerminan dari founding father ini. Calvin memegang prinsip bahwa iman yang benar adalah iman yang diikuti oleh daya pikir. Suatu dogma gereja hanya dapat dimengerti dan diterima bukan hanya bergantung pada pola pikir masyarakat yang menerima, tetapi juga bergantung pada daya pikir masyarakat yang menerimanya. Oleh sebab itu pendidikan sangat penting, dan Calvin sebagai tempat pembelajaran. ${ }^{36}$

Pada zaman Calvin, pendidikan hanya terarah pada persiapan untuk para imam gereja Roma Katolik dan bukan pendidikan bagi masyarakat. Dalam pandangan Calvin, pemahaman atas pentingnya pendidikan berbeda dengan gereja zaman itu. pengelolaan gereja ada di tangan penatua yang tentunya orang awam. Mereka harus membaca Alkitab, mereka harus tahu pengakuan imannya. Karena orang awam terlibat dalam pengelolaan gereja mereka harus belajar dasar-dasar bergereja. Maka, gereja Calvinis sangat menekankan pentingnya pendidikan.

\footnotetext{
${ }^{36}$ Alifius Areng Mutak, Reformasi dan Pendidikan Kristen: Menelusuri Warisan Reformasi dalam Pendidikan Kristen, (STT Aletheia, Lawang Jawa Timur: Jurnal Theologia Aletheia Vol.19 No.13 September 2017) p. 109

${ }^{37}$ Ibid, p. 110
}

Kontribusi Calvin terhadap pendidikan Kristen dapat dilihat dari upaya yang ia lakukan yaitu dengan menafsirkan dan menerapkan pengajaran Kitab Suci dan teologi yang berkaitan dengan kehidupan pribadi, gereja, dan bangsa. Dalam bidang pendidikan, pendekatan Calvin yang menerima teori-teori dan metodologi pendidikan kontemporer namun tujuan pendidikan harus tetap sesuai dengan tujuan dari pedoman perilaku dari Kitab Suci yaitu hal-hal yang menyangkut tentang karakter ilahi dan disiplin kehidupan Kristiani. ${ }^{37}$

Aristarchus dalam tulisannya tentang pengaruh Calvinisme dalam kehidupan Gereja dan Pendidikan di Indonesia mengatakan bahwa legasi pandangan teologis Calvinis berpengaruh terhadap kehidupan gereja-gereja di Indonesia. Praktek kehidupan gereja Calvinis di Indonesia juga dapat dikatakan mengikuti praktik kehidupan gereja Calvinis pembawanya termasuk di dalamnya perhatian terhadap dunia pendidikan. ${ }^{38}$ Lebih lanjut lagi dikatakan bahwa memang secara tradisional gerejagereja Presbyterian maupun Reformed sangat menekankan standar yang tinggi untuk pendidikan dan pelayanan gerejanya.

\footnotetext{
38 Aristarchus Sukarto, Pengaruh Calvinisme dalam Kehidupan Gereja dan Pendidikan di Indonesia (Jakarta: Komisi pengkajian Teologi Gereja Kristen Indonesia Sinode Wilayah Jawa Barat, 2010) p.218
} 
Karena keyakinan ini, dapat dikatakan kemana saja orang-orang Calvinis bergerak, maka mereka akan membawa atau mendirikan sekolah-sekolah bukan hanya mendirikan gereja.

Jika kita kaitkan kontribusi Calvinisme yang melebur dalam pendidikan nasional, maka kita melihat bahwa sekolah-sekolah Kristen di tanah air turut mengambil peran yang tidak sedikit. Maksudnya adalah pemikiran Calvin mengalir dalam gereja Calvinis yang mengakui bahwa pendidikan masyarakat amat penting bukan saja sebagai benteng Protestantisme tetapi juga sebagai fondasi kuat bagi negara. Gereja sekarang ini menghadapi begitu banyak tantangan. Namun gereja harus peka terhadap zaman, konteks sosial dimana ia berada adalah hal yang sudah sepatutnya. Para pendeta, pengajar terus memikirkan pola, metode agar kualitas iman jemaat terus berkembang dan bersifat transformatif. Saat ini masih dijumpai orang Kristen yang tanpa pertobatan, tanpa disiplin gerejawi, tanpa pengakuan, tanpa menjadi murid, tanpa salib bahkan tanpa Yesus Kristus. Orang Kristen demikian hanya menginginkan suatu kehidupan yang enak-enak yang mengakibatkan kerusakan terhadap orang Kristen dimana-mana. Memang dalam sekarang ini ada suatu pesimistis terhadap kualitas jemaat yang dimiliki gereja-gereja saat ini, dimana cukup banyak yang dapat dijumpai hanyalah jemaat yang ingin hidup dalam anugerah yang murah. Masih terdapat orang yang bermabuk-mabukan, masih dijumpai kasus perselingkuhan, perzinahan, penipuan, perceraian dan lainlain yang sudah dianggap biasa, tidak didisiplin gerejawikan.

Ini merupakan masalah yang krusial. Para pemimpin gereja harus terusmenerus menanamkan prinsip-prinsip penting dalam kehidupan berjemaat; pertama, hidup adalah karunia Tuhan Allah. Bahwa Allah punya rencana yang sempurna dalam hidup setia anak-anakNya. Kedua, hidup dalam dunia ini punya tujuan dan berada dalam rencana Allah demi kemuliaan-Nya. Penyelenggaraan pendidikan Kristen bergereja harus menolong jemaat untuk memahami serta menaati perintah Allah dan tujuan-Nya bagi umat.

Pendidikan bergereja bagi jemaat bukan hanya untuk belajar tentang Firman Tuhan saja tetapi agar dapat mengaplikasikannya dalam hidup seharihari. Seperti kata Calvin, Pendidikan dalam gereja ada untuk mengatur secara tertib agar warga gereja semakin sadar akan kekurangan mereka tetapi kemudian dapat bersukacita oleh karena pengalaman kehidupan mereka dalam doa, Alkitab dan pelayanan terhadap sesama. Seluruh warga memahami Alkitab sebagai ilmu, bukan hanya sekedar buka Alkitab, baca dan 
sampai disitu. Jikalau mereka memahami Alkitab yang adalah Firman Tuhan maka karakter mereka akan terus berkembang. Gereja-gereja arus utama khususnya di Sulawesi Utara yang berlatar belakang Calvinis sadar betul bahwa sumber pengetahuan sejati hanya ada dalam Kitab Suci sebagai Firman (Sola Scriptura). Disini para pendeta atau pengajar terfokus pada makanan atau nutrisi dari pendidikan yang diberikannya. Gereja adalah guru bagi jemaat karena Tuhan sendirilah yang memilih untuk mengajar mereka melalui pengajar-pengajar dengan cara yang sesuai dengan kebutuhan dan kapasitas. Pengajaran Iman Kristen di gereja yang mendalam, menyeluruh dan lengkap harus dilaksanakan agar kualitas iman mereka terus bertumbuh dan semakin dekat dengan Kristus.

\section{KESIMPULAN}

Yohanes Calvin adalah seorang
teolog besar pada zamannya, dan
pemikirannya memengaruhi kehidupan
kekristenan sampai sekarang ini.
Pengaruhnya dalam bidang-bidang
kehidupan sosial sangat besar dan hal tersebut dilakukannya hanya demi kemuliaan Tuhan. Pemikirannya dalam pendidikan juga patut kita apresiasi dengan begitu baik. Calvin menerapkan sistem gerejawi yang begitu ketat, disiplin untuk membentuk para pengajar gereja, baik pendeta maupun guru agama untuk melayani, mengajar dengan sungguhsungguh untuk memberikan kualitas iman jemaat yang bertanggung jawab kepada Tuhan. Gereja harus terus menerus mewarisi semangat Calvin untuk memajukan kualitas pendidikan jemaat agar tidak mudah ditipu dengan berbagai macam pemikiran yang tidak berdasarkan prinsip-prinsip Alkitab. Ada begitu banyak aspek pemikiran Calvin yang dapat dikaji dan dapat digunakan sebagai suatu refleksi teologis dan analisa akademis bagi kehidupan gereja dan insititusi pendidikan kita.

\section{DAFTAR PUSTAKA}

Abineno, J.L.C. Garis-garis Besar Hukum Gereja, Jakarta: BPK Gunung Mulia, 2009

Bakker, Anton dan Achmad Charis Zubair, Metodologi Penelitian Filsafat, Yogyakarta: Kanisius, 1989

Battajery, Agustinus dan Th.van den End (Peny.), Ecclesia reformata semper reformanda: dua belas tulisan mengenai Calvin dan Calvinisme, Jakarta: BPK Gunung Mulia, 2015

Berkhof, Louis dan Cornelius Van Til, Dasar Pendidikan Kristen, Surabaya: Momentum, 2004

Boehlke, Robert R. Sejarah Perkembangan Pikiran dan Praktek Pendidikan Agama Kristen: dari Plato sampai Ignatius Loyola, Jakarta: BPK Gunung Mulia, 2009

Cortret, Bernard. Calvin: a Biography, translated by: M. Wallace 
McDonald, Michigan: Publishing Company, 2000

De Jonge, Christiaan. Apa itu Calvinisme? Jakarta: BPK Gunung Mulia, 2012

Calvin, Yohanes. Institutio-Pengajaran Agama Kristen, diseleksi oleh Th. Van den End / diterjemahkan oleh Winarsih dan JS. Aritonang, Jakarta: BPK Gunung Mulia, 2015

Commentaries on the Epistles of Paul to the Galatians and Ephesians, trans. William Pringle, Grand Rapids: Eerdmans, 1948

Commentary on I Corinthians 1:20 in Commentary on the Epistles of Paul to the Corinthians; Institutes I.xv. 6.

Commentary on Titus 1:10-12; in Calvin's Commentaries vol. XXI, trans. by. William Pringle. Institutes II.ii

Commentary on I Corinthians 1:20 in Commentary on the Epistles of Paul to the Corinthians; Institutes I.xv. 6.

Commentary on Titus $1: 10-12 ; \|$ in Calvin's Commentaries vol. XXI, trans., by William Pringle; Institutes II.ii.

Hall, David W. Warisan John Calvin: pengaruhnya di dunia modern, terj.Lanna Wahyuni, Surabaya: Momentum, 2010

dan Peter A. Lillback (ed.) Penuntun ke dalam Theologi Institutes Calvin : Esai-esai dan Analisis, Terj. Lanna Wahyuni, Surabaya: Momentum, 2009

Calvin di Ranah Publik. Surabaya: Momentum, 2011

Hoffecker, W. Andrew. Membangun Wawasan Dunia Kristen, Volume 1: Allah, Manusia, dan Pengetahuan, terj. Peter Suwandi
Wong, Surabaya: Momentum, 2006

Homrighausen, Pendidikan Agama Kristen, Jakarta: BPK Gunung Mulia, 2003

Kaelan, M.S, Metode Penelitian Kualitatif bidang Filsafat, Paradigma: Yogyakarta, 2005

Lere Dawa, Martin Febriana, Peran Pendidikan Kristen Protestan John Calvin, Malang: Jurnal Theologia Aletheia, 2005

Lukito, Daniel Lucas 500 Tahun Yohanes Calvin: Pengetahuan tentang Allah adalah Testing Ground untuk mengenal Manusia. SAAT: Malang, Jurnal Veritas Vol.10. No.1, 2009

McGrath, Allister E. A Life of John Calvin, Oxford: Basil Blackwell, 1990

Meeter, Henry. Pandangan-pandangan Dasar Calvinisme, Surabaya: Momentum, 2014

Mutak, Alifius Areng. Reformasi dan Pendidikan Kristen: Menelusuri Warisan Reformasi dalam Pendidikan Kristen, STT Aletheia, Lawang Jawa Timur: Jurnal Theologia Aletheia Vol.19 No.13 September 2017

Niesel, Wilhelm. The Theology of Calvin, terj. Harold Knight, London: Lutterworth, 1956

Osmer, Richard Robert. A Teachable Spirit: Recovering the Teaching Office in the Church, Westminster John Knox Press Louisville, Kentucky 1990

Pranoto, Irwan. Relevansi Konsep Spiritual Calvin dalam Konteks Masa Kini, SAAT Malang: Jurnal Veritas, 2001

Rapar, Jan Hendrik. Jabatan Gerejawi Menurut Calvin dan Implikasinya bagi Organisasi dan Tata Gereja di Masa Kini, Jurnal Educatio 
Christi No.22. Tahun XX, UKI Tomohon: Februari 2015

Riwon, Alfrey. Esensi dan Relevansi Teologi Reformasi. Jakarta: Buletin Pillar GRII, 2007

Setlight, Johanna. Suatu Peran Gereja dalam memperlengkapi Guruguru Sekolah Minggu untuk Pelayanan Pendidikan Agama Kristen GMIM, Tesis; Jakarta: SEAGEST, 1994

Subagyo, Andras B. Pengantar Riset Kuantitatif dan Kualitatif Termasuk Riset Teologi dan Keagamaan, Bandung: Kalam Hidup, 2004

Sumakul, HWB. Panggilan Iman dalam Teologi Luther dan Calvin; suatu kajian Etika Sosial Politik dalam Gereja Reformasi, Jakarta: BPK Gunung Mulia, 2014

Sukarto, Aristarchus. Pengaruh Calvinisme dalam Kehidupan Gereja dan Pendidikan di Indonesia. Jakarta: Komisi pengkajian Teologi Gereja Kristen Indonesia Sinode Wilayah Jawa Barat, 2010

Tanya, Eli. Gereja dan Pendidikan Kristen: Mencermati Peranan Pedagogis Gereja. STT: Cipanas, 1999

Th. van den End, ed., Enam Belas Dokumen Dasar Calvinisme, Jakarta: BPK Gunung Mulia, 2011

Tidwell, Charles A. Educational Ministry of a Church, Nashville: Broadman Press, 2000

Warfield, B.B. Calvin and Calvinism, Oxford: Oxford University Press, 1931

Wendel, Francois. Calvin: Asal usul dan

Perkembangan Pemikiran Religiusnya.

Surabaya: Momentum, 2010 